\title{
Extractive Spectrophotometric Determination of Samarium with Chlorophosphonazo III
}

\author{
J. Uhrovčík, J. Lesný \\ University of SS. Cyril and Methodius in Trnava \\ Department of Ecochemistry and Radioecology \\ Nám. J. Herdu 2, SK-91701, Trnava, The Slovak Republic \\ E-mail: jozef.uhrovcik@ucm.sk
}

Abstract: A rapid and sensitive extractive spectrophotometric method has been developed for the determination of samarium using $0.04 \%$ Chlorophosphonazo III in $1 \mathrm{~mol} \mathrm{~L}^{-1}$ hydrochloric acid media after extraction into isoamylalcohol. Absorbance was measured in 1-cm cell and the complex has a sensitive absorption peak at $667 \mathrm{~nm}$. The complex of Sm(III)-Chlorophosphonazo III is formed instantly in organic phase and remains stable at least for 2 hours with constant absorbance under normal laboratory conditions. Validity of Beer's law was verified in range 0-10 $\mu \mathrm{g}$ $\mathrm{Sm}$ (III) per $10 \mathrm{~mL}$ of the organic phase with an estimated molar absorptivity $\varepsilon_{667} \sim 1.1410^{5} \mathrm{~mol}^{-1} \mathrm{~L}^{-1} \mathrm{~cm}^{-1}$. Limit of detection (3- $\sigma$ approach) reached $0.22 \mu \mathrm{g} \mathrm{Sm}(\mathrm{III})$. Some foreign cations interference in samarium determination has been checked. The method has been applied on spiked sample of mineral water. Obtained results of apparent recovery were found in very good agreement with acceptable range. The percent relative standard deviation for repeatability was less than $\pm 5 \%(n=3)$.

Keywords: samarium, Chlorophosphonazo III, spectrophotometry, extraction, isoamylalcohol

\section{Introduction}

Besides its industrial applications samarium is used first of all in microelectronics as dopant and in optics. Samarium(III) occurs in nature in the Earth's crust in the form of the mineral monazite with different proportions and it is followed by uranium, thorium and other lanthanides. Determination of samarium is a specific analytical problem due to its chemical similarity to the other rare earth metals and uranium. Therefore, high precision and low detection limit are required for samarium determination in most of real samples. Samarium is exclusively determined by inductively coupled plasma with mass spectrometry (ICP-MS) and inductively coupled plasma with atomic emission spectrometry methods $[6,12]$. However, spectrophotometric determination represents suitable and relatively cheap alternative in comparison with above mentioned methods. The application of organic reagents for spectrophotometric determination of samarium is well known. Chlorophosphonazo III (Fig. 1) belongs to azo-dyes based on 
chromotropic acids. It is commercially available and soluble in water and diluted acids. The reagent has ability to form stable chelates and can work in strongly acidic medium eliminating the chances of partial hydrolysis of metal ions to be determined. Its analytical properties were described for the first time by soviet research group led by Alexander Nemodruk [9].

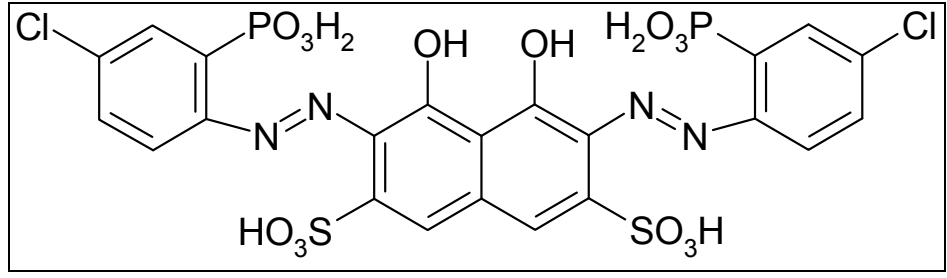

Figure 1. Structure of Chlorophosphonazo III.

Chlorophosphonazo III is a complexing reagent primarily suggested for the spectrophotometric determination of lanthanides [3-5], actinides [1, 11] and alkaline earth metals $[10,17]$. The utilization of Chlorophosphonazo III as a complexing reagent for spectrophotometric determination of various elements was markedly preferred in the 1960s and 70s. The reagent has valuable advantages such as an excellent time stability of the absorbance and a relatively wide linear range, while the major disadvantage is its rather high price. Chlorophosphonazo III still has a justified place among the complexing agents utilized in trace analysis and the interest in its analytical applications significantly grows in recent years. The first use of Chlorophosphonazo III for extractive spectrophotometric determination of samarium and other lanthanides from media of diluted hydrochloric acid into organic solvent has been published by Taketatsu and co-workers [14]. The extraction of Sm(III)-Chlorophosphonazo III complex led to an increase of selectivity and sensitivity of the relevant determination. Similar effect was observed at extractive spectrophotometric determination of thorium with Chlorophosphonazo III into isoamylalcohol [16]. While the successful applicability of Chlorophosphonazo III for spectrophotometric quantification of samarium in different matrices is indisputable, the number of works dealing with detailed evaluation of particular determinations by means of Chlorophosphonazo III with extraction into organic solvents is surprisingly limited [15]. The presented study is devoted to evaluation of important validation parameters for extractive spectrophotometric determination of samarium using Chlorophosphonazo III with extraction of formed complex into isoamylalcohol.

\section{Experimental}

\subsection{Reagents}

All used reagents were of analytical grade and all solutions were prepared in deionised water. Samarium stock solution with concentration $10 \mu \mathrm{g} \mathrm{mL}^{-1}$ was prepared by appropriate dilution of standard solution (Fluka Analytical, Austria) and it was stabilized with addition of concentrated nitric acid (Merck, Germany). The concentration of solution of the Chlorophosphonazo III (Dojindo Laboratories, Japan) was $0.04 \%$ (w./v.). The medium of measured solutions has been adjusted by addition of 
concentrated hydrochloric acid (Mikrochem, Slovakia). The foreign ions stock solutions were prepared by dilution of their standard solutions (Fluka Analytical, Austria). Isoamylalcohol (Panreac Química, Spain) was used for the extraction of formed Sm(III)-Chlorophosphonazo III complex.

\subsection{Apparatus}

All absorbance measurements were performed using the Cary WinUV 50 (Varian Inc., Australia) double-beam spectrophotometer equipped with 1-cm quartz cells. Every point of calibration curve was measured for five times and the average values were taken into account in next calculations. Laboratory centrifuge Universal 320R (Hettich, Germany) was used for removing of droplets of water from organic phase. Deionised water with specific conductivity $<0.054 \mu \mathrm{S} \mathrm{cm}^{-1}$ was prepared by means of ultrapure water system Millipore Simplicity 185 (Millipore, Germany).

\subsection{Recommended procedure}

Place a sample containing $0-10 \mu \mathrm{g}$ of samarium in a $100 \mathrm{~mL}$ Squibb-type separatory funnel. Adjust the aqueous phase to $1 \mathrm{~mol} \mathrm{~L}^{-1}$ with appropriate addition of concentrated hydrochloric acid. Add $1.5 \mathrm{~mL}$ of aqueous $0.04 \%$ Chlorophosphonazo III solution and mix. Add exactly $10 \mathrm{~mL}$ of isoamylalcohol and shake for 2 minutes. Remove aqueous phase and treat the organic phase by centrifugation (4500 rpm, 5 minutes). Measure the absorbance of the clear organic phase at $667 \mathrm{~nm}$ against a reagent blank as a reference. Obtain the samarium quantity from a calibration curve by method of external calibration. In case of matrix effect is necessary to apply the method of standard addition. After equilibration, the volume of the organic phase decreased due to the slight solubility of isoamylalcohol in water. In order to avoid the use of volume change correction is advantageous to consider absolute amount of samarium $\left(\mathrm{m}_{0}\right)$ instead the molar or mass concentration in all next calculations.

\subsection{Real sample analysis}

To assess the applicability of the presented method, mineral water sample was analyzed from the brook "Brusnianka" using the recommended procedure. The sample was spiked with different known amounts of samarium.

\section{Results and discussion}

The most important chemical variables were assessed to obtain the highest sensitivity for the determination of samarium. Sm(III)-Chlorophosphonazo III complex in isoamylalcohol showed two absorption peaks, namely at $616 \mathrm{~nm}$ and $667 \mathrm{~nm}$ (Fig. 2). Due to the higher value of analytical signal and favourable value of background absorption (dashed line) the latter wavelength was selected. 


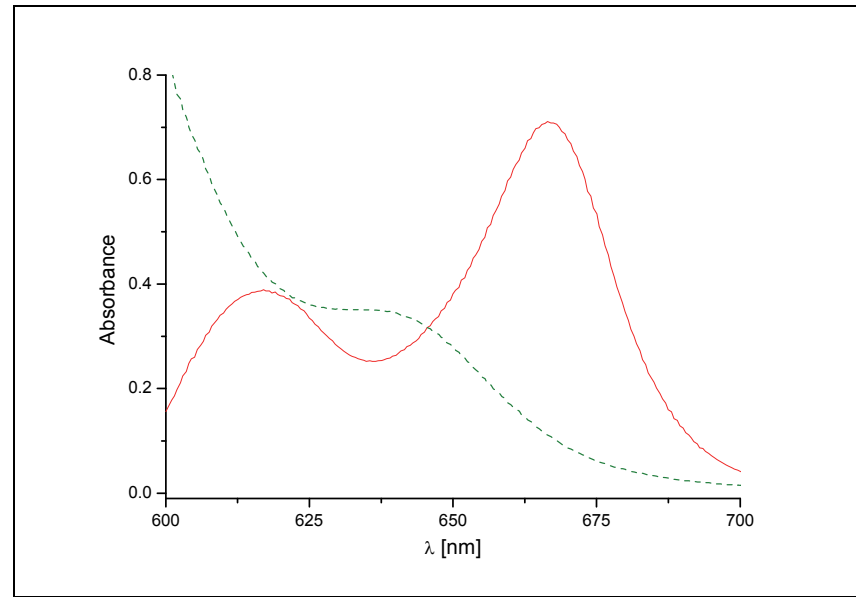

Figure 2. Absorption spectrum of Sm(III)-Chlorophosphonazo III complex against a reagent blank. $m_{0} S m(I I I)=10 \mu g ; c(H C l)=1 \mathrm{~mol} \mathrm{~L}^{-1}$;

$V($ Chlorophosphonazo III) $=1 \mathrm{~mL}$.

\subsection{The effect of acidity}

As shown in Figure 3, absorbance of samarium complex in the organic phase reached the maximal value at hydrochloric acid concentration of $0.5 \mathrm{~mol} \mathrm{~L}^{-1}$, but at this concentration of acid remained some Chlorophosphonazo III in aqueous phase. For this reason $1 \mathrm{~mol} \mathrm{~L}^{-1}$ hydrochloric acid was used in further investigations.

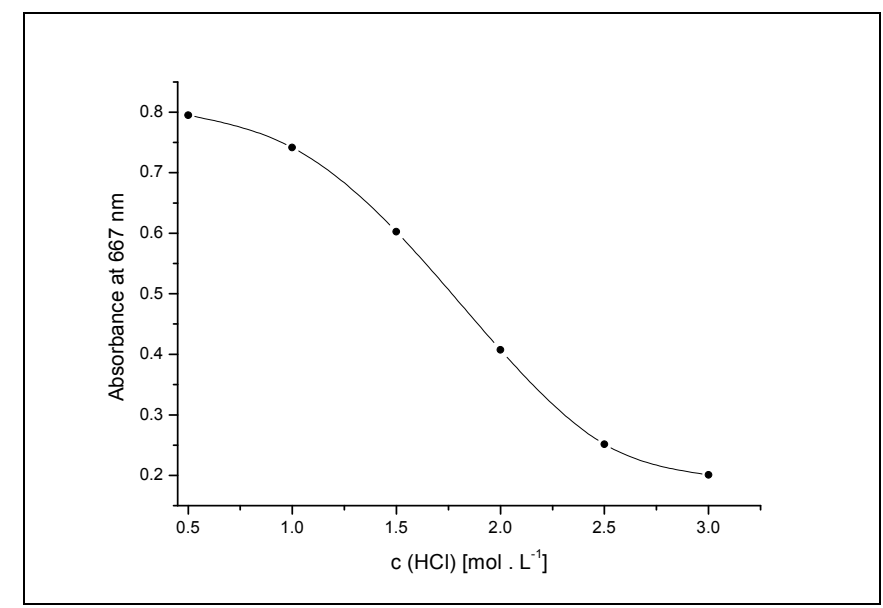

Figure 3. Effect of acidity of aqueous phase on absorbance of organic phase. $m_{0} \operatorname{Sm}(I I I)=10 \mu g ; V($ Chlorophosphonazo III) $=1 \mathrm{~mL}$. 


\subsection{The effect of amount Chlorophosphonazo III}

In the Fig. 4 is showed that absorbance of organic phase is almost constant when $1.4 \mathrm{~mL}$ of complexing agent solution is added into aqueous phase. For convenience, the volume of $1.5 \mathrm{~mL}$ of $0.04 \%$ Chlorophosphonazo III solution was used for subsequent measurements.

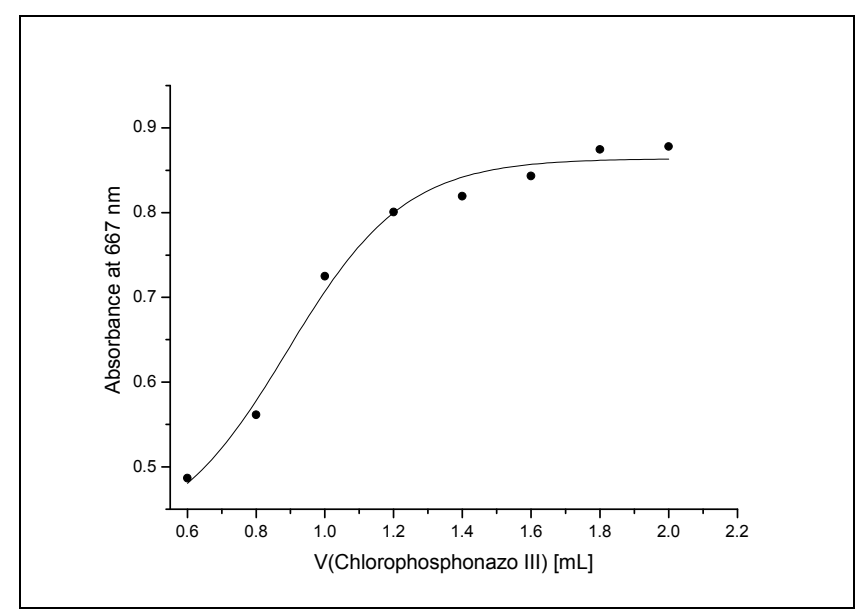

Figure 4. Effect of added volume of Chlorophosphonazo III on the absorbance of organic phase. $m_{0} \mathrm{Sm}(\mathrm{III})=10 \mu \mathrm{g} ; \mathrm{c}(\mathrm{HCl})=1 \mathrm{~mol} \mathrm{~L}^{-1}$.

\subsection{Shaking and recovery}

The degree of extraction of Sm(III)-Chlorophosphonazo III into isoamylalcohol was examined by the following experiment: $10 \mu \mathrm{g}$ of samarium was extracted according to the recommended procedure and samarium remaining in the aqueous phase was examined by adding another Chlorophosphonazo III solution, extracting with $10 \mathrm{~mL}$ of the organic solvent and measuring the absorbance of the organic phase. It was confirmed that extraction is quantitative in two steps and the degree of extraction in the first step is $\sim 90 \%$, but this finding is not critical for analytical application of suggested method. Extraction of samarium complex is very rapid. Shaking for 30 seconds was enough to attain equilibrium when the complexing agent was added to the aqueous phase and shaked with addition of isoamylalcohol.

The validity of Beer's law was established from 0 to $10 \mu \mathrm{g}$ of samarium in organic phase by application of recommended procedure (Figure 5). Calculated equation of regression reached value: $A=0.77 \pm 0.001 m_{0}+0.007$ (data in parentheses represent uncertainty of parameters). Coefficient of determination had value $\mathrm{R}^{2}=0.9990$. Value of molar absorptivity was estimated from equation of regression $\varepsilon_{667} \sim 1.1410^{5} \mathrm{~mol}^{-1} \mathrm{~L}^{1} \mathrm{~cm}^{-1}$. It was not revealed presence of any constant systematic error(s) by application of Student $t$-test (significance level $\alpha=0.05$ ). 


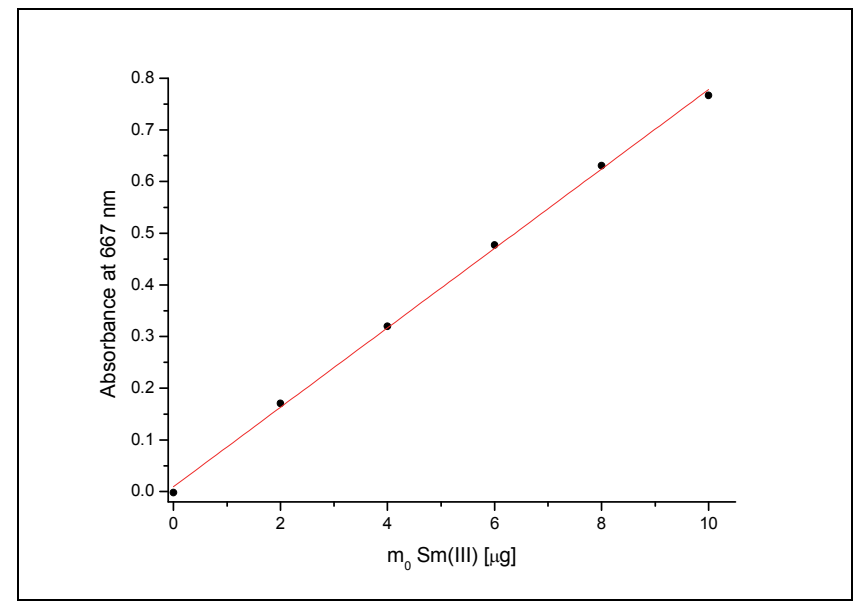

Figure 5 Absorbance of Sm(III)-Chlorophosphonazo III complex as a function of samarium absolute amount against a reagent blank.

The values of limit of detection (LOD) and limit of quantification (LOQ) were calculated by 3- $\sigma$ and 10- $\sigma$ approach [2] and ULA2 approach [8] as well. In the case of computation by $3-\sigma$ and $10-\sigma$ approach residual standard deviation $\left(s_{y / x}\right)$, standard deviation of $y$-intercept $\left(s_{b}\right)$ and standard deviation of blank $\left(\mathrm{s}_{\text {blank }}\right)$ were applied [7]. Results of calculations are given in Table 1.

Table 1. $L O D$ and $L O Q$ values calculated by using two different approaches.

\begin{tabular}{|ccc|cc|}
\hline \multicolumn{3}{|c|}{ 3- $\boldsymbol{\sigma}$ and 10- $\boldsymbol{\sigma}$ approach } & \multicolumn{2}{|c|}{ ULA2 approach } \\
\hline \multirow{2}{*}{$\mathbf{s}_{\mathbf{b l a n k}}{ }^{\dagger}$} & LOD $[\mu \mathrm{g}]$ & 0.22 & LOD $(\alpha=0.05)[\mu \mathrm{g}]$ & 0.34 \\
& LOQ $[\mu \mathrm{g}]$ & 0.72 & LOQ $(\alpha=0.05)[\mu \mathrm{g}]$ & 1.03 \\
\hline \multirow{2}{*}{$\mathbf{s}_{\mathbf{y} / \mathbf{x}}$} & LOD $[\mu \mathrm{g}]$ & 0.39 & LOD $(\alpha=0.01)[\mu \mathrm{g}]$ & 0.61 \\
& LOQ $[\mu \mathrm{g}]$ & 1.31 & LOQ $(\alpha=0.01)[\mu \mathrm{g}]$ & 1.82 \\
\multirow{2}{*}{$\mathbf{s}_{\mathbf{b}}$} & LOD $[\mu \mathrm{g}]$ & 0.28 & ${ }^{\dagger} 10$ blank determinations & \\
& LOQ $[\mu \mathrm{g}]$ & 0.95 & & \\
\hline
\end{tabular}

Reference measurement of samarium content in the mineral water sample was carried out by ICP-MS method in accredited laboratory of the State Geological Institute of Dionýz Štúr in Spišská Nová Ves (Slovakia). Reference concentration value of samarium was $3 \mathrm{ng} \cdot \mathrm{L}^{-1}$. So on the basis of this finding, mineral water sample can be considered a suitable model for potential matrix effect study. For this reason the sample of mineral water was spiked with $2 ; 5$ and $7 \mu \mathrm{g}$ of samarium and then analyzed according to recommended procedure. Results for obtained apparent recovery and repeatability are shown in Table 2 . 
Table 2. Obtained data for repeatability and trueness of measurement $(n=3)$.

\begin{tabular}{|c|c|c|}
\hline $\boldsymbol{m}_{\boldsymbol{0}} \boldsymbol{S m}(\boldsymbol{I I I})[\boldsymbol{\mu g}]$ & apparent recovery [\%] & relative standard deviation [\%] \\
\hline 2 & 100.2 & \pm 5.2 \\
\hline 5 & 101.6 & \pm 1.8 \\
\hline 7 & 98.8 & \pm 1.4 \\
\hline
\end{tabular}

Absence or presence of matrix effect was established by the second independent technique, namely by method of standard addition. On the basis of obtained results it may be concluded that influence of matrix effect on the trueness of determination was not confirmed at this type of sample.

The optical density of measured complexes was found constant at least for 2 hours under normal laboratory conditions within the linear range of the proposed method (temperature $22^{\circ} \mathrm{C}$ ).

The influence of some potentially interfering ions was checked and their impact is summarized in Table 3 . Three replicate determinations were carried out for each interfering ion.

Table 3. Effect of chosen cations on samarium determination with Chlorophosphonazo III after extraction into organic solvent. $m_{0} S m(I I I)=5 \mu g$.

\begin{tabular}{|l|c|}
\hline foreign ion & deviation [\%] \\
\hline $\mathrm{Ca}(\mathrm{II})^{(\mathbf{a})}(1: 100)$ & +1.4 \\
\hline $\mathrm{Fe}(\mathrm{III}){ }^{(\mathbf{a})}(1: 30)$ & +3.4 \\
\hline $\mathrm{Eu}(\mathrm{III})^{(\mathbf{b})}(10: 1)$ & +39.9 \\
\hline $\mathrm{La}(\mathrm{III})^{(\mathbf{b})}(10: 1)$ & +3.8 \\
\hline $\mathrm{Mg}(\mathrm{II})^{(\mathbf{a})}(1: 100)$ & +2.4 \\
\hline $\mathrm{Th}(\mathrm{IV})^{(\mathbf{b})}(10: 1)$ & +10.1 \\
\hline $\mathrm{U}(\mathrm{VI})^{(\mathbf{b})}(1: 1)$ & +38.5 \\
\hline \multicolumn{2}{|c|}{} \\
\hline
\end{tabular}

The average value of three replicate Sm(III) Chlorophosphonazo III absorbances (not containing foreign ions) was taken into account as a reference value. Mass ratio between $\mathrm{Sm}$ (III) and given interfering ion is listed in the Table 3. The target analyte can be effective separated from most of interfering ions by means of convenient type of cation-exchange resin, for example AG50W-X8 (BioRad, Germany) [13].

\section{Conclusions}

A rapid and sensitive extractive spectrophotometric method was developed for samarium determination using $0.04 \%$ Chlorophosphonazo III in diluted hydrochloric acid. The gained complex exhibited two absorption peaks, namely at $616 \mathrm{~nm}$ and $667 \mathrm{~nm}$, respectively, from which the latest one was a set for all subsequent measurements. The relevant complex remained under laboratory conditions stable at least for 2 hours maintaining the constant value of absorbance. Beer's law obeyed in the range from 0 to $10 \mu \mathrm{g}$ per $10 \mathrm{~mL}$ of organic phase. Only U(VI), Th(VI) 
and Eu(III) interfered seriously in model solutions and the presence of above mentioned cations led to a significant increase of absorbance. The application of the investigated method for mineral water sample analysis shows favourable results concerning trueness and repeatability. However, its utilization for determination of the target analyte in very complex matrices containing significant quantity of interferences will require implementation of appropriate separation procedures. Due to the fact that the concentration of samarium in most of real matrices is negligible, it is necessary to include the suitable types of preconcentration techniques into analytical cycle.

\section{References}

[1] Bykhovtsova, T. T., Tserkovnitskaya, I. A.: Photometric determination of uranium(VI) by means Chlorophosphonazo III in organic solutions after the extraction separation of uranium by means of trialkylamines, Zhurnal Analiticheskoi Khimii, vol. 32, no. 5, pp. 745-750, 1977

[2] Currie, L. A.: Nomenclature in evaluation of analytical methods including detection and quantification capabilities. IUPAC Recommendations, Pure and Applied Chemistry, vol. 67, no. 10, pp. 1699-1723, 1995

DOI: $10.1351 /$ pac199567101699

[3] Dedkova, V., Shvoeva, O., Savvin, S.: Sorption-spectrophotometric determination of lanthanum, gadolinium, and ytterbium using chlorophosphonazo III on a PANF-Chel adsorbent, Journal of Analytical Chemistry, vol. 66, no. 10, pp. 937940, 2011

DOI: $10.1134 / \mathrm{S} 1061934811080089$

[4] Gajduk, O. V., Pantaler, R. P., Blank, A. B.: Spectrophotometric determination of cerium in the presence of $\mathrm{Ca}, \mathrm{Sr}$, and $\mathrm{Al}$, Zavodskaya Laboratoryia, vol. 73, no.3, pp. 15-18, 2007

[5] Ivanov, V. N., Ermakova, N. V.: Sorption of Lanthanum, Terbium, and Erbium Complexes of Some Mono- and Bisazoderivatives of Chromotropic Acid in the Presence of Surfactants, Journal of Analytical Chemistry, vol. 18, no. 3, pp. 217-224, 2003

DOI: $10.1023 / \mathrm{A}: 1022678202473$

[6] Li, B., Sun, Y., Yin, J.: Determination of cerium, neodymium and samarium in biological materials at low levels by isotope dilution inductively coupled plasma mass spectrometry, Journal of Analytical Atomic Spectrometry, vol. 14, no. 12, pp. $1843-1848,1999$

DOI: $10.1039 / \mathrm{A} 905346 \mathrm{H}$

[7] Miller, J. N., Miller, J. CH.: Statistics and Chemometrics for Analytical Chemistry, Ellison Horwood, Chichester, 2005

[8] Mocák, J., Bond, A. M., Mitchell, S., Scollary, G.: A statistical overview of standard (IUPAC and ACS) and new procedures for determining the limits of detection and quantification: Application to voltammetric and stripping techniques, Pure and Applied Chemistry, vol. 69, no. 2, pp. 297-328, 1997 DOI: $10.1351 /$ pac199769020297 
[9] Nemodruk, A. A., Novikov, Y. P., Lukin, A. M., Kalinina I. D.: 2,7-Bis-(4-Chloro2-phosphonbenzene-azo)-1,8-dihydroxynapthalene-3,6-disulphonic acid (ChlorophosphonazoIII). A new reagent for the photometric determination of uranium, Zhurnal Analiticheskoi Khimii, vol. 16, pp. 180-184, 1961.

[10] Noda, K., Sato, Y., Miura, T., Katayama, K., Kojima, R.: Development of novel measurement assay for calcium in serum by the chlorophosphonazo-III vanadate method, Annals of Clinical Biochemistry, vol., 47, no. 5, pp. 440-446, 2010 DOI: $10.1258 /$ acb.2010.010013

[11] Oguma, K., Suzuki, T., Saito, K.: Determination of uranium in seawater by flowinjection preconcentration on dodecylamidoxime-impregnated resin and spectrophotometric detection, Talanta, vol., 84, no. 5, pp. 1209-1214, 2011 DOI: 10.1016/j.talanta.2010.12.020

[12] Paama, L., Pämoja, E., Must, M., Perämäki, P.: Optimal conditions for europium and samarium determination in cathodoluminophors by inductively coupled plasma atomic emission spectrometry, Journal of Analytical Atomic Spectrometry, vol. 16 , no. 11 , pp. 1333-1336, 2001

DOI: $10.1039 / \mathrm{B} 105520 \mathrm{H}$

[13] Strelow, F. W. E.: Quantitative separation of lanthanides and scandium from barium, strontium and other elements by cation-exchange chromatography in nitric acid, Analytica Chimica Acta, vol. 20, pp. 249-254, 1980 DOI: $10.1016 / \mathrm{S} 0003-2670(01) 84368-3$

[14] Taketatsu, T., Kaneko, M., Kono, N.: Solvent extraction-spectrophotometric determination of rare earths with chlorophosphonazo-III, Talanta, vol. 21, no. 1, pp. $87-91,1974$

DOI: $10.1016 / 0039-9140(74) 80065-2$

[15] Vilímec, J., Jakubec, K.: Direct spectrophotometric determination of rare earths in organic extracts with chlorophosphonazo III, Microchemical Journal, vol. 35, no. 3, pp. $325-327,1987$

DOI: $10.1016 / 0026-265 X(87) 90118-4$

[16] Yamamoto, T.: Extraction-photometric determination of thorium with chlorophosphonazo-III, Analytica Chimcia Acta, vol. 63, no. 1, pp. 65-70, 1973 DOI: $10.1016 / \mathrm{S} 0003-2670(01) 82174-7$

[17] Zenki, M., Masutani, T., Yokoyama, T.: Repetitive determination of calcium ion and regeneration of a chromogenic reagent using Chlorophosphonazo III and an ion exchanger in a circulatory flow injection system, Analytical Sciences, vol. 18, no. 10, pp. 1137-1140, 2002

DOI: $10.2116 /$ analsci.18.1137 